\title{
An 86-Year-Old Female with Mitral Regurgitation and Significant Pectus Excavatum
}

\author{
Raphael Tasar $^{1}$ Sophie Tkebuchava ${ }^{1}$ Mahmoud Diab ${ }^{1}$ Torsten Doenst ${ }^{1}$ \\ ${ }^{1}$ Department of Cardiothoracic Surgery, University Hospital Jena, \\ Jena, Germany \\ Thorac Cardiovasc Surg Rep 2019;8:e37-e40. \\ Address for correspondence Torsten Doenst, MD, PhD, Department \\ of Cardiothoracic Surgery University Hospital Jena, Am Klinikum 1, \\ Jena 07747, Germany \\ (e-mail: Doenst@med.uni-jena.de; benjamin.gloy@med.uni-jena.de).
}

\begin{abstract}
Keywords

- mitral regurgitation

- mitral valve repair

- pectus excavatum excavatum. deformation?

\section{Introduction}

Mitral valve repair is the gold standard of current treatment options for structural mitral regurgitation. Since surgery always poses an acute risk of complication or death, various issues are repeatedly discussed in heart teams, specifically age, expected effect of surgery, and technical aspects of surgery. We present a case representative for many of these discussions.
\end{abstract}

Background We report the case of minimally invasive mitral valve repair in an 86-yearold female with symptomatic structural mitral regurgitation and severe pectus

Case Description The case summarizes four areas of repetitive heart team discussions. First, should an 86-year-old patient still be treated invasively? Second, if so, should treatment be interventional or surgical? Third, if surgical, should we replace or repair at that age and fourth which surgical access is best with respect to her chest

Conclusion We chose to surgically repair the valve using a minimally invasive approach. The patient was extubated 3 hours after surgery and discharged after 7 days.

\section{Case Description}

An 86-year-old female presented with dyspnea (New York Heart Association Class III) and angina pectoris (CCS II) due to severe structural mitral valve regurgitation (MVR) (large prolapse of P2, - Fig. 1A and B). In addition, she suffered from an exceptional case of pectus excavatum. The computed tomography images show a distance of only $10 \mathrm{~cm}$ between the sternum and the vertebral column (-Fig. 2). Otherwise, the patient was in good condition, but she suffered massively from her dyspnea.

Heart team discussion revealed four areas of controversy in this nice lady. First, should we treat an 86-year-old patient, who is asymptomatic at rest? Second, should we operate on this lady or use an interventional approach? Third, do we need to repair the valve at this age? Fourth, how should we deal with the pectus excavatum?

We decided for a minimally invasive approach with mitral valve repair and discuss our decision-making process below. For the operation, we established cardiopulmonary bypass percutaneously in the right groin and used a right lateral mini-thoracotomy for access to the heart (-Fig. 3). ${ }^{1}$ We clamped the aorta and applied Bretschneider cardioplegia antegrade in standard fashion. Valve exposure was critical due to the chest deformation. However, the very lateral access required only limited atrial elevation possible with a standard atrial retractor providing acceptable visualization of the entire valve apparatus. We resuspended a large P2 segment with three $12 \mathrm{~mm}$ Gore-Tex loops. Since the remaining valve segments were rather small and tender, we selected a $28 \mathrm{~mm}$ rigid saddle annuloplasty ring (RSAR, Abbott, United States). In addition, we closed a patent foramen ovale. The operation was free of complications. The patient left the operating room without residual mitral regurgitation (-Fig. 1C and D) and was extubated 3 hours later. She was discharged from the hospital after an uneventful recovery period at postoperative day 7 . received

June 11, 2019

accepted

July 30, 2019
DOI https://doi.org/

10.1055/s-0039-1700881. ISSN 2194-7635. (c) 2019 Georg Thieme Verlag KG
Stuttgart · New York

License terms

((1) $\circledast$ 

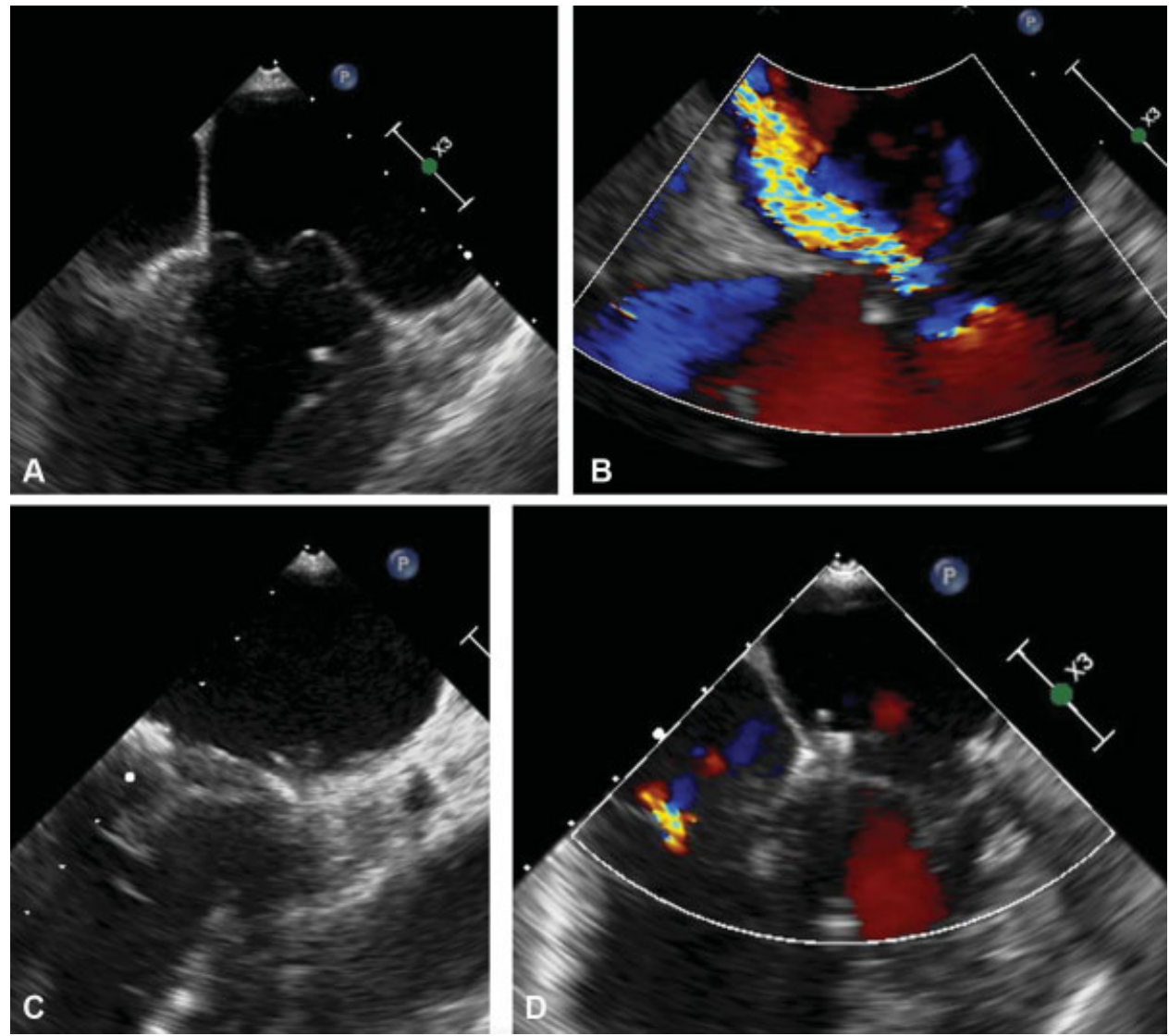

Fig. 1 Pre- and postoperative echocardiographic images demonstrating severe mitral regurgitation due to a large prolapsing P2 segment of the posterior leaflet (A, B) and the postoperative result with a competent valve and a significant amount of coaptation (C, D).
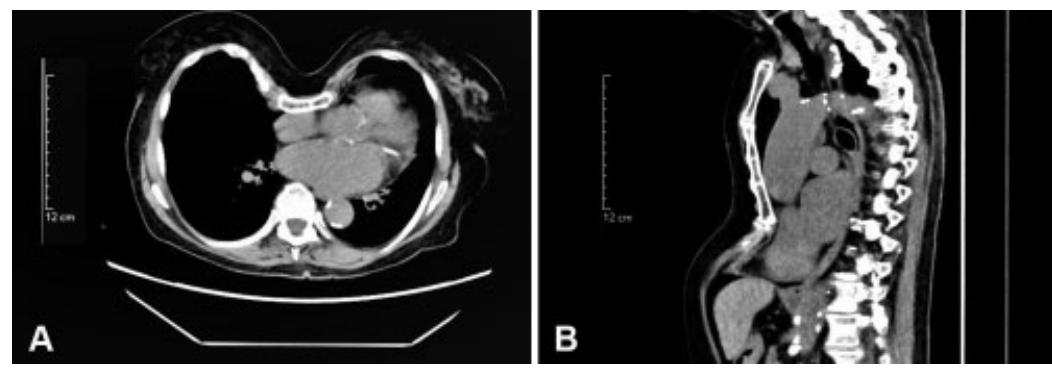

Fig. 2 Computed tomography imaging of the chest illustrating the severe form of pectus excavatum ( $A$ and $B$ ) with displacement of the heart to the left chest $(A)$.

\section{Discussion}

This case summarizes a whole series of representative aspects important in our everyday decision-making for patients with mitral valve problems. The most important ones were part of our heart team discussion. The evidence for our decisions is summarized in the - Table $\mathbf{1}$ and is further illustrated below.

\section{Should We Operate on an 86-Year-Old Patient?}

Due to improved medical care and higher life expectancy, cardiac surgery patients are continuously getting older. Older patients ( $\geq 80$ years) tend to have more comorbidities then younger patients (such as hypertension, prior myocardial infarction, congestive heart failure, stroke, and malig- nancies) and age is an accepted independent risk factor in cardiac surgery. ${ }^{2}$ Since recovery after surgical procedures is slower, older patients often require longer in-hospital stay and a time for return to normal daily activities. ${ }^{3,4}$ Thus, the decision to operate on an 86-year-old patient who is asymptomatic at rest may not be as easy as if the patient were 66 years old, because the prognostic impact of surgery may be less relevant. We addressed this issue in a recent editorial and opted for an individualized approach because most older patients have clear understandings of risks and benefits if they are properly informed. ${ }^{5}$ The patient presented here had a strong wish for treatment because the inability to be active was unbearable for her. In addition, the treatment effect of mitral valve repair is also documented in octogenarians. Thus, the question of which treatment option is best arose. 


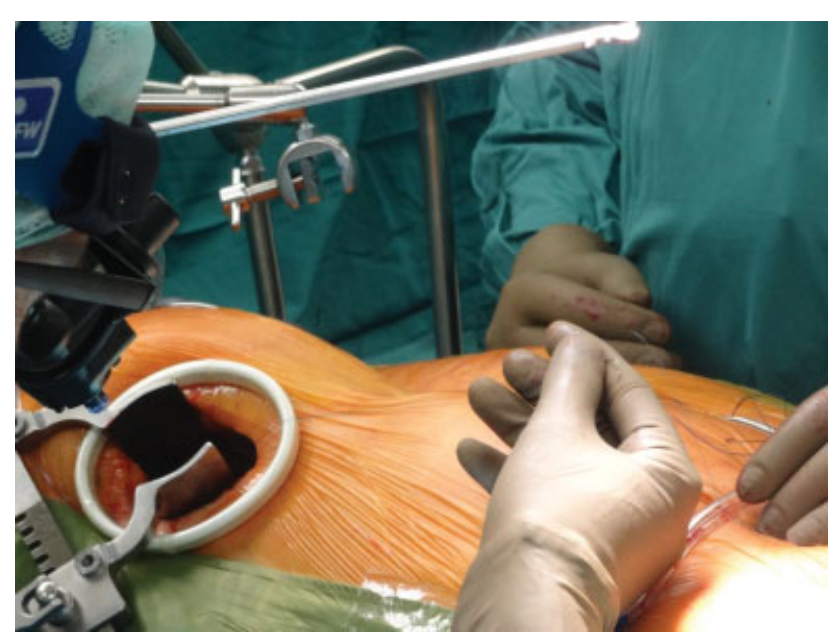

Fig. 3 Intraoperative picture illustrating the lateral mini-thoracotomy in this patient with severe pectus excavatum.

Table 1 Summary of heart team discussions in our case as well as rationale and evidence for decision-making

\begin{tabular}{|l|l|l|}
\hline $\begin{array}{l}\text { Area of } \\
\text { discussion }\end{array}$ & $\begin{array}{l}\text { Rationale for } \\
\text { decision-making }\end{array}$ & $\begin{array}{l}\text { Refer- } \\
\text { ence }\end{array}$ \\
\hline $\begin{array}{l}\text { Surgery at } \\
86 \text { years for severe } \\
\text { structural MR? }\end{array}$ & $\begin{array}{l}\text { Class 1 recommendation } \\
\text { for surgical repair } \\
\text { No age limit in } \\
\text { recommendation }\end{array}$ & 8 \\
\hline $\begin{array}{l}\text { Surgery versus } \\
\text { intervention }\end{array}$ & $\begin{array}{l}\text { Surgery greater chance for } \\
\text { durable repair. Guidelines } \\
\text { mention intervention only } \\
\text { with prohibitive risk }\end{array}$ & 8,11 \\
\hline $\begin{array}{l}\text { MIS versus } \\
\text { sternotomy }\end{array}$ & $\begin{array}{l}\text { Key outcomes } \\
\text { not different. MIS } \\
\text { faster recovery }\end{array}$ & 12,13 \\
\hline $\begin{array}{l}\text { Repair versus } \\
\text { replacement }\end{array}$ & $\begin{array}{l}\text { Repair better survival even } \\
\text { at older age }\end{array}$ & 10 \\
\hline Pectus excavatum & $\begin{array}{l}\text { Individual approach based } \\
\text { on anatomy }\end{array}$ & \\
\hline
\end{tabular}

Abbreviations: MIS, minimally invasive surgery; MR, mitral regurgitation.

\section{Surgical or Interventional Approach?}

Nowadays, there are various approaches available to treat MVR. For our patient, the updated guidelines support a surgical approach due to her symptomatic, structural MVR with a flail P2 segment, an ejection fraction of 53\%, and an intermediate operative risk (STS Score 5.1\%). ${ }^{6}$ An alternative consideration may be a MitraClip application for its lesser invasiveness in this situation. Although this decision would not be directly backed by the guidelines, the results from EVEREST II (which was primarily performed in structural MR patients) demonstrate results that would be acceptable for an 86-year-old patient. However, long-term outcome appears to be related to the quality of the repair ${ }^{7}$ and, due to the large P2 segment, we were afraid that the clipping result may not be optimal. We, therefore, chose to operate, a decision which is fully supported by the guidelines. ${ }^{8}$

\section{What Would be the Best Surgical Approach and Treatment of the Valve?}

Given the unusual anatomy and the critical location of the sternum displacing the heart, both a sternotomy and a classic anterolateral mini-thoracotomy approach appeared as a challenge. We decided to approach the valve through a mini-thoracotomy that was more lateral than usual (-Fig. 3). The approach paid off and the limited retraction of the left atrial roof with a conventional retractor sufficed for complete exposure of the valve.

Valve inspection revealed a classic large prolapse of P2. Although replacement of this valve in this patient would probably be an acceptable option, we decided to perform a classic P2 repair using the loop technique with resuspension of the prolapsing segment with three 12-mm loops. Based on our repair rate of $99 \%$ for valves with an intention to repair, ${ }^{5}$ this appeared as a safe option in our hands. We believe that the classic resection method is not optimal in these cases because the prolapsing segment could not have been resected completely and the remaining parts often require additional Gore-Tex suspension. The final result was a completely competent valve with significant coaptation ( - Fig. 1C and D), which now leads not only to a reduction in symptoms but also to a significant extension of life expectancy. ${ }^{9,10}$ The lady was discharged after 7 days and was free of dyspnea, fatigue, or edema and showed an increased ability to exercise at 4 weeks follow-up. The statistics based on the literature and her clinical presentation now predict that she has a greater chance to become older than 90 years than most of us reading this article.

This case nicely illustrates that an evidence-based approach to decision-making taking individual risks and competencies into account may result in optimal outcomes. Old age per se is certainly not a contraindication for surgery.

\section{Abbreviations}

STS

EVEREST II A Study of the Evalve Cardiovascular Valve

Repair System - Endovascular Valve Edge-toEdge REpair STudy

\section{Conflict of Interest}

None.

\section{References}

1 Moschovas A, Amorim PA, Nold M, et al. Percutaneous cannulation for cardiopulmonary bypass in minimally invasive surgery is associated with reduced groin complications. Interact Cardiovasc Thorac Surg 2017;25(03):377-383

2 Iung B, Cachier A, Baron G, et al. Decision-making in elderly patients with severe aortic stenosis: why are so many denied surgery? Eur Heart J 2005;26(24):2714-2720

3 Wang W, Bagshaw SM, Norris CM, Zibdawi R, Zibdawi M, MacArthur R; APPROACH Investigators. Association between older age and outcome after cardiac surgery: a population-based cohort study. J Cardiothorac Surg 2014;9:177

4 Zingone B, Gatti G, Rauber E, et al. Early and late outcomes of cardiac surgery in octogenarians. Ann Thorac Surg 2009;87(01):71-78 
e40 Minimally Invasive Mitral Valve Repair in an 86-Year-Old Female Tasar et al.

5 Faerber G, Doenst T. Cardiac (valve) surgery in the elderly-who decides you are too old? JThorac Cardiovasc Surg 2018;155(04):1461-1462

6 O'Gara PT, Grayburn PA, Badhwar V, et al. 2017 ACC Expert Consensus Decision Pathway on the Management of Mitral Regurgitation: a report of the American College of Cardiology Task Force on Expert Consensus Decision Pathways. J Am Coll Cardiol 2017;70(19):2421-2449

7 Suri RM, Clavel MA, Schaff HV, et al. Effect of recurrent mitral regurgitation following degenerative mitral valve repair: longterm analysis of competing outcomes. J Am Coll Cardiol 2016;67 (05):488-498

8 Baumgartner H, Falk V, Bax JJ, et al; ESC Scientific Document Group. 2017 ESC/EACTS Guidelines for the management of valvular heart disease. Eur Heart J 2017;38(36):2739-2791

9 Mick SL, Keshavamurthy S, Gillinov AM. Mitral valve repair versus replacement. Ann Cardiothorac Surg 2015;4(03):230-237
10 Silaschi M, Chaubey S, Aldalati O, et al. Is mitral valve repair superior to mitral valve replacement in elderly patients? Comparison of short- and long-term outcomes in a propensitymatched cohort. JAm Heart Assoc 2016;5(08):e003605

11 Takagi H, Ando T, Umemoto T. Direct and adjusted indirect comparisons of perioperative mortality after sutureless or rapid-deployment aortic valve replacement versus transcatheter aortic valve implantation. Int J Cardiol 2017;228: 327-334

12 Doenst T, Lamelas J. Do we have enough evidence for minimallyinvasive cardiac surgery? A critical review of scientific and nonscientific information. J Cardiovasc Surg 2017;58:613-623

13 Mihaljevic T, Koprivanac M, Kelava M et al. Value of Robotically Assisted Surgery for Mitral Valve DiseaseRobotically Assisted Mitral Valve SurgeryRobotically Assisted Mitral Valve Surgery. JAMA Surgery 2014;149:679-686 